\title{
Adverse drug reactions or events in children with assessment of causality and severity: a retrospective analysis from Bhavnagar
}

\author{
Jayendra R. Gohil*, Aniket B. Sarwade, Hardik R. Chauhan, Jay R. Jasani, Hinal R. Gujarati
}

Department of Pediatrics, Government Medical College, Sir T. G. Hospital, Bhavnagar, Gujarat, India

Received: 19 October 2020

Accepted: 19 November 2020

*Correspondence:

Dr. Jayendra R. Gohil,

Email: jayukids@yahoo.com

Copyright: (C) the author(s), publisher and licensee Medip Academy. This is an open-access article distributed under the terms of the Creative Commons Attribution Non-Commercial License, which permits unrestricted non-commercial use, distribution, and reproduction in any medium, provided the original work is properly cited.

\begin{abstract}
Background: Objective was to study the occurrence of adverse drug reactions in pediatric age group in a tertiary care hospital setting.

Methods: A retrospective study was undertaken to analyze adverse drug events in pediatrics wards of a tertiary care hospital. Any event marked as 'suspected adverse drug reaction' was included in the study and ADR forms were analyzed for causality and severity. Other parameters like age and sex, class of drug, types of ADR, commonly involved systems and polypharmacy were studied.

Results: Total 74 cases of admitted patients (13 deaths: 11 infants, 6 neonates) with severe ADR were studied of whom $39 \%$ were females. Antimicrobials were the commonest drug class (54\%) with Skin most commonly involved. $77 \%$ cases were of probable category according to Naranjo's scale of causality assessment. $11 \%$ cases were prescribed polypharmacy.

Conclusions: Antibiotics were the class of drug causing maximum ADRs. The commonest system involved was skin. Redness, itching \& rashes were the common symptoms. Antimicrobials should be used judiciously. Polypharmacy should be avoided. ADR reporting should be strengthened. Extra vigilance is required for infants and neonate's prescriptions.
\end{abstract}

Keywords: Adverse drug reaction, Adverse drug event, Children, Naranjo scale, Pharmacovigilance

\section{INTRODUCTION}

An adverse drug reaction (ADR), also known as adverse drug event (ADE), is defined as any noxious, unintended and undesired effect of a drug which occurs at a dose used in humans for prophylaxis, diagnosis, therapy or modification of physiological functions. ${ }^{1}$ WHO defines pharmacovigilance as the science and activities relating to the detection, assessment, understanding and prevention of adverse effects; or any other drug related problems. ADR burden the health system by not only increasing the mortality \& morbidity but also the expenses and length of hospital stay. Pharmacovigilance is used to identify, appraise, comprehend and avert ADRs with the eventual aim to develop secure and coherent utilization of medications. ${ }^{2}$ It gives a measure of the burden of drug induced morbidity. More than half of ADRs could be averted with better prescription care. ${ }^{3}$

Data in adults cannot be relied upon to predict ADRs in children. Some ADRs have shown exclusivity to pediatric age group. Recent examples of ADRs detected exclusively in the pediatric age group include: greenish discoloration of teeth following ciprofloxacin in neonates; gastric outlet obstruction due to prostaglandin infusion in neonates; fatal hepatic dysfunction following valproic acid in developmentally delayed, mentally retarded \& children with congenital anomalies of less than 2 years of age; benign intracranial hypertension due to recombinant growth hormone therapy in children; isotretinoin causing depression in adolescents. ${ }^{4-8}$ 
The safety profile of a drug thus marketed with its testing done on adults can vary significantly when used in children. ${ }^{9}$ Due to these difficulties ADR reporting is one method to get information regarding adverse drug reactions occurring in children based on which changes in dose adjustments, withdrawal of drug usage in children or other such measures may be undertaken to ensure safety.

\section{Aim and objectives}

Aim and objectives were to analyze retrospectively ADR forms for studying its patterns, common drug classes involved, causality assessment (assessed by Naranjo's algorithmic scale) and severity and, orienting clinicians towards the ADRs occurring in pediatric age group and help them ensure optimal drug usage in children safely.

\section{METHODS}

A retrospective analysis study was undertaken by reviewing the ADR forms from pediatrics department. Data was analyzed for the ADRs that were reported in the period of 1 year and 2 months interval (1 August 2015 to
30 September 2016). Discretion of information acquired was secured \& confidentiality was maintained during the study.

\section{Inclusion criteria}

Any undesirable and unintended event that was marked as suspected ADR and reported from inpatients between the ages $0-12$ years.

\section{Exclusion criteria}

Tuberculosis drugs, non-infectious adverse transfusion reactions (NIATR), blood transfusion reaction (BTR), and adverse events following immunisation (AEFI).

This was analysed as per Naranjo probability scale, (Table 1) as it is easy to apply, though it is not that sensitive or specific as to be called an excellent method of certainty. The Roussel Uclaf causality assessment method (RUCAM) is another scale for evaluating the likelihood that a medication has caused drug induced liver injury.

Table 1: Naranjo ADR probability scale. ${ }^{10}$

\begin{tabular}{|c|c|c|c|c|}
\hline Question & Yes & No & Don't know & Score \\
\hline Are there previous conclusive reports on this reaction? & +1 & 0 & - & +1 \\
\hline Did the adverse event appear after the suspected drug was administered? & +2 & -1 & 0 & +2 \\
\hline $\begin{array}{l}\text { Did the adverse reaction improve when the drug was discontinued or a specific } \\
\text { antagonist was administered? }\end{array}$ & +1 & 0 & 0 & +1 \\
\hline Did the adverse event reappear when the drug was re-administered? & +2 & -1 & - & 0 \\
\hline $\begin{array}{l}\text { Are there alternative causes (other than the drug) that could on their own have } \\
\text { caused the reaction? }\end{array}$ & -1 & +2 & - & -1 \\
\hline Did the reaction reappear when a placebo was given? & -1 & +1 & - & +1 \\
\hline $\begin{array}{l}\text { Was the drug detected in blood (or other fluids) in concentrations known to be } \\
\text { toxic? }\end{array}$ & +1 & 0 & - & 0 \\
\hline $\begin{array}{l}\text { Was the reaction more severe when the dose was increased or less severe when } \\
\text { the dose was decreased? }\end{array}$ & +1 & 0 & - & 0 \\
\hline $\begin{array}{l}\text { Did the patient have a similar reaction to the same or similar drugs in any } \\
\text { previous exposure? }\end{array}$ & +1 & 0 & 0 & 0 \\
\hline Was the adverse event confirmed by any objective evidence? & +1 & 0 & 0 & +1 \\
\hline
\end{tabular}

Scoring: $\geq 9$ Definite ADR, 5-8 Probable ADR, 1-4 Possible ADR, 0 Doubtful ADR

\section{RESULTS}

Total 74 cases of ADRs were reported in the study duration of 1 year and 2 months, of which $61 \%$ occurred in males and $39 \%$ in female. More than one drug was prescribed in about $11 \%$ cases (polypharmacy). Class of drug causing ADRs, adverse effects, systems involved and severity of ADRs are as in Tables 2 to 4.

Antibiotics were the most common drug to cause adverse events as it is widely prescribed. Anti-convulsants was next as acute empiric therapy has to be followed by a long time (Table 2). Most adverse events were related to the skin and gastrointestinal system as expected, followed by respiratory, blood, cardiovascular, thermal, and nervous system (Table 3).

Table 2: Class or group of drugs.

\begin{tabular}{|l|l|}
\hline Drug class & N \\
\hline Antibiotics & 40 \\
\hline Anti-convulsants & 18 \\
\hline Immunoglobulin & 4 \\
\hline Antiviral & 4 \\
\hline NSAIDS, steroids & 4 \\
\hline Surfactant & 4 \\
\hline Anti-emetic & 3 \\
\hline Immunosuppressant & 1 \\
\hline
\end{tabular}


Table 3: Adverse events (number).

\begin{tabular}{|c|c|}
\hline Symptoms/signs & $\mathbf{N}$ \\
\hline $\begin{array}{l}\text { Redness, itching, urticaria } \\
\text { facial flushing, alopecia }\end{array}$ & 18 \\
\hline $\begin{array}{l}\text { Abdominal pain, distension } \\
\text { loose stool, nausea, vomiting }\end{array}$ & 17 \\
\hline $\begin{array}{l}\text { Bronchospasm, shallow respiration } \\
\text { pulmonary hemorrhage }\end{array}$ & 9 \\
\hline $\begin{array}{l}\text { Pancytopenia, thrombocytopenia } \\
\text { blood in stool, hematuria }\end{array}$ & 7 \\
\hline Anaphylaxis, shock & 6 \\
\hline Fever, rigors, & 5 \\
\hline Headache, eye pain, photophobia & 4 \\
\hline Tremors, head nodding, hypotonia, & 4 \\
\hline Edema face, eyelid; neck rigidity & 4 \\
\hline Hepatitis & 3 \\
\hline Metabolic, arrhythmia, weight gain* & $6 *$ \\
\hline $\begin{array}{l}\text { Lupus, hirsuitism, acute kidney } \\
\text { Injury (AKI), gum hyperplasia }\end{array}$ & $4 \#$ \\
\hline
\end{tabular}

The gastrointestinal system was most commonly affected as opposed to the expected skin involvement, as this study looked at admitted patients and therefore serious condition and severe events where skin was not the only manifestation. No case of Steven Johnson syndrome or erythema multiform was there, probably due to high awareness leading to lesser use of sulpha or other drugs (Table 4).

Table 4: System involved in adverse drug event.

\begin{tabular}{|l|l|}
\hline System & N \\
\hline Gastrointestinal & 22 \\
\hline Skin & 19 \\
\hline Respiratory & 17 \\
\hline Central nervous & 10 \\
\hline Thermoregulatory & 6 \\
\hline Blood & 5 \\
\hline Genitourinary/ Renal & 4 \\
\hline Cardiovascular* & 4 \\
\hline
\end{tabular}

*Does not include anaphylaxis 6 cases.

Table 5: Severity assessment.

\begin{tabular}{|l|l|}
\hline Seriousness of reaction & N \\
\hline Hospitalization-initial or prolonged & 39 \\
\hline $\begin{array}{l}\text { Required intervention to prevent } \\
\text { permanent impairment/ damage }\end{array}$ & 11 \\
\hline Life threatening & 14 \\
\hline Death & 13 \\
\hline Disability & 0 \\
\hline Congenital anomaly & 0 \\
\hline Non serious-no intervention & 7 \\
\hline
\end{tabular}

Table 5 shows that according to Naranjo's scale (Table 1) of causality assessment, $77.3 \%$ cases were of probable causality score, possible score was for $13.6 \%$ cases and 9.1\% cases had definite score. This assessment merely shows the probability of occurring and does not mean cause and effect; but rather an association, whether strong or weak, between an adverse event and a drug or drugs.

Beside this, 13 (17\%) death associations were reported (Table 6). $83 \%$ patients recovered. ${ }^{11,12}$

Table 6: Association of adverse events with deaths.

\begin{tabular}{|c|c|c|c|}
\hline S. no. & Age & Drug & Complication \\
\hline 1 & Neonate & Surfactant & $\begin{array}{l}\text { Pulm } \\
\text { haemorrhage }\end{array}$ \\
\hline 2 & Neonate & Surfactant & $\begin{array}{l}\text { Pulm } \\
\text { haemorrhage }\end{array}$ \\
\hline 3 & Neonate & Amikacin & Renal \\
\hline 4 & Infant & NSAID & Bleeding \\
\hline 5 & Infant & Phenobarbitone & Resp failure \\
\hline 6 & 3 years & $\begin{array}{l}\text { anti-snake } \\
\text { venom }\end{array}$ & Resp failure \\
\hline 7 & Neonate & Midazolam & Resp failure \\
\hline 8 & Neonate & Midazolam & Resp failure \\
\hline 9 & Neonate & Midazolam & Resp failure \\
\hline 10 & Infant & azithromycin iv & Cardiac arrest \\
\hline 11 & Infant & Levetiracetam & Neutropenia $^{11}$ \\
\hline 12 & 8 years & Midazolam & Cardiac arrest ${ }^{12}$ \\
\hline 13 & Infant & Piperacillin & NEC \\
\hline
\end{tabular}

Out of 13 deaths only 2 were above 1 -year-age, others were all neonates or infants $<1$-year age. We need to be more careful and vigilant while using drugs in first year and first month of life. And be on the lookout for ADR or an Adverse Event all the time with a high degree of suspicion.

\section{DISCUSSION}

Higher incidence is found in males $(61 \%)$. Contrary finding was depicted in a study where $67 \%$ females were found to be affected. ${ }^{13}$ Number of drugs used increases the risk of ADRs. In our study we found $11 \%$ cases were prescribed more than one drug. A decrease in ADRs was noticed with decrease in number of drugs. Drug interactions may add up the adverse effects.

In one study it is reported that $30 \%$ of neonates receiving more than 10 drugs get no less than one ADR and, in our study, we found that all five $(11 \%)$ neonates with ADR were receiving more than 4 drugs. Exponential rise of ADRs in neonates has been seen when exposed to four or more medications as also new-born and infants are at a higher risk due to immature metabolizing system. ${ }^{14}$ However it is unavoidable sometimes in a neonate as sepsis markers are not well-defined. ${ }^{15}$ It is recommended to avoid poly-pharmacy if it is not essential and to report the drug intake by each child to discover potential sources of heterogeneity between studies. As such it is a longadvocated practice to use drugs as judiciously as possible, 
may it be the number of drugs or classes of drugs used. In our study antibiotics drugs were responsible for maximum of about $54 \%$ cases of ADRs, which has also been reflected in various studies. In India, antibiotics are used in a high number of prescriptions, so this may be one reason for this class of drugs to appear as major class responsible for causing ADRs. One study has reported similar findings; about $67 \%$ cases were because of antibiotics. Most of the drugs used in adult patients are not commonly used in pediatric age group such as antihypertensive, lipid lowering agents, anti-diabetics, etc. So, antibiotics were common class of drugs causing ADRs in children.

In our study anaphylactic reactions were seen in $8.4 \%$ of which antibiotics, sodium valproate and anti-diphtheritic serum were contributing, in contrast to one study in which antibiotics were the major group contributing to anaphylaxis. $^{16}$

Also, fever, abdominal pain and respiratory depression altogether accounts for $18.3 \%$ of cases. Vomiting, nausea, diarrhea, chills and rigors were other common manifestations found apart from other ADRs. Skin was the most common system involved $(28.2 \%)$ with next GIT (21.1\%). Most of the pediatric studies frequently use Naranjo's algorithm for ADR assessment. It is simple and brief, its validity and reliability have been demonstrated in adults but not in children. ${ }^{10,17}$ According to Naranjo's scale of causality assessment, in our study $77.3 \%$ cases were of probable causality score, $13.6 \%$ had possible score and $9.1 \%$ had definite score. Classification and evaluation of ADRs in terms of severity can recognize the root cause of ADRs and appropriate steps by healthcare providers can improve paediatric pharmacovigilance.

\section{CONCLUSION}

Antibiotics were the class of drug causing maximum ADRs. The commonest system involve was skin. Redness, itching and rashes were the common symptoms. Thirteen deaths (11 infants including 6 neonates) had association with a potential ADE. Polypharmacy was seen with more reactions including in neonates.

Antimicrobials (including antibiotics) should be used judiciously. Polypharmacy should be avoided. ADR reporting should be strengthened.

\section{Recommendations}

We need to strengthen the ADR monitoring, reporting and awareness programs. Avoidance of indiscriminate use of drugs especially antibiotics, polypharmacy, including in neonates and early recognition of ADRs will decrease associated morbidity and mortality and drug resistance due to suboptimal ADR reporting practices. As neonates and infants are a very high-risk group for deaths, we need to be vigilant for infant's prescriptions.

\section{ACKNOWLEDGEMENTS}

We thank the pharmacology department for the guidance.

Funding: No funding sources

Conflict of interest: None declared

Ethical approval: The study was approved by the Institutional Ethics Committee

\section{REFERENCES}

1. WHO definition: Adverse event/ reaction, Pharmacovigilance. 2002. Available at: who.int/medicines/areas/quality_safety/safety_efficac $\mathrm{y} /$ trainingcourses/definitions.pdf. Accessed on 18 July 2019.

2. Montastruc JL, Sommet A, Lacroix I, Olivier P, Durrieu G, Damase-Michel C, et al. Pharmacovigilance for evaluating adverse drug reactions: value, organization, and methods. Jo Bon Spi. 2006;73(6):629-32.

3. Chien JY, Ho RJ. Drug delivery trends in clinical trials and translational medicine: evaluation of pharmacokinetic properties in special populations. J. Pharm Sci. 2011;100:53-8.

4. Lumbiganon P, Pengsaa K, Sookpranee T. Ciprofloxacin in neonates and its possible adverse effect on the teeth. Pediatr Infect Dis J. 1991;10:61920.

5. Dagan O, Peled N, Babin P, Silver M, Barker G, Koren G. Prostaglandin-induced antral hyperplasia in neonates: clinical experience and dose-response characteristics. Developmen Pharmacol Therapeut. 1993;20:14-9.

6. Dreifuss FE, Santilli N, Langer DH, Sweeney KP, Moline KA, Menander KB. Valproic acid hepatic fatalities: a retrospective review. Neurology. 1987;37(3):379.

7. Crock PA, McKenzie JD, Nicoll AM, Howard NJ, Cutfield W, Shield LK, et al. Benign intracranial hypertension and recombinant growth hormone therapy in Australia and New Zealand. Acta Paediatrica. 1998;87(4):381-6.

8. Wysowski DK, Pitts M, Beitz J. An analysis of reports of depression and suicide in patients treated with isotretinoin. J Am Acad Dermatol. 2001;45(4):515-9.

9. Clavenna A, Bonati M. Adverse drug reactions in childhood: A review of prospective studies and safety alerts. Arch Dis Child. 2009;94:724-8.

10. National Institute of Diabetes and Digestive, Kidney Diseases. LiverTox. 2019. Available at: ncbi.nlm.nih.gov/books/NBK548069/bin/Naranjoasse ssment.pdf Accessed Sept 2020. Accessed on 12 July 2020.

11. Gohil JR, Agarwal TS. Levetiracetam Adverse Drug Reaction: Pancytopenia. J Pediatr Neurosci. 2018;13(1):116-7. 
12. Gohil JR, Jindal SV. Cardiotoxicity Associated with Midazolam in a Patient with Diphtheria. Curr Drug Saf. 2019;14(1):57-9.

13. Priyadharsini R, Surendiran A, Adithan C, Sreenivasan S, Sahoo FK. A study of adverse drug reactions in pediatric patients. J Pharmacol Pharmacother. 2011;2:277-80.

14. Kaushal R, Bates DW, Landrigan C, McKenna KJ, Clapp MD, Federico F, et al. Medication errors and adverse drug events in pediatric inpatients. J Am Medic Assoc. 2001;285(16):2114-20.

15. Baker DM, Bell LM. Unpredictability of Serious Bacterial Illness in Febrile Infants from Birth - 1 month. Arch Pediatr Adolesc Med. 1999;153(5):50811 .
16. Patel TK, Patel PB, Barvaliya MJ, Tripathi CB. Drug-induced anaphylactic reactions in Indian population: A systemic review. Indian J Crit Care Med. 2014;18:796-806.

17. Lamabadusuriya SP, Sathiadas G. Adverse drug reactions in children requiring hospital admission. Ceylon Med J. 2003;48:86-7.

Cite this article as: Gohil JR, Sarwad AB, Chauhan HR, Jasani JR, Gujarati HR. Adverse drug reactions or events in children with assessment of causality and severity: a retrospective analysis from Bhavnagar. Int J Basic Clin Pharmacol 2020;9:18837. 